\title{
$O$ registro de práticas interventivas da Terapia Ocupacional na educação inclusiva ${ }^{1}$
}

\author{
Tatiana Barbieri Bombarda ${ }^{\mathrm{a}}$, Marina Silveira Palhares ${ }^{\mathrm{b}}$ \\ aDepartamento de Terapia Ocupacional, Universidade Federal de São Carlos - UFSCar, São Carlos, SP, Brasil. \\ bPrograma de Pós-Graduação em Terapia Ocupacional, Universidade Federal de São Carlos - UFSCar, \\ São Carlos, SP, Brasil.
}

\begin{abstract}
Resumo: Considerando a importância dos registros na prática da Terapia Ocupacional é necessário instigar nos profissionais um olhar mais criterioso na efetivação de suas anotações, assim como estimular o desenvolvimento de pesquisas voltadas a investigação da prática documental. A elaboração dos registros provém da necessidade de se ter informações decorrentes da assistência como via de orientação e fiscalização sobre o serviço prestado e acerca da responsabilidade técnica adotada; bem como da compreensão das anotações como um recurso valioso fornecedor de dados para pesquisas. O presente estudo buscou caracterizar os terapeutas ocupacionais do estado de São Paulo que atuam na educação inclusiva e identificar como são realizados os registros de suas práticas interventivas. Como instrumento foi utilizado um questionário estruturado disponibilizado em site específico da web por tempo predeterminado, sendo os dados obtidos analisados por meio de estatística descritiva. Os participantes foram 55 terapeutas ocupacionais atuantes no processo de educação inclusiva e cadastrados no Conselho Regional de Fisioterapia e Terapia Ocupacional da $3^{\text {a }}$ Região. Os resultados demonstraram a narrativa livre como o modelo de registro mais utilizado e fragmentações das informações relacionadas ao processo de guarda das anotações. Tais dados evidenciaram fragilidade na sistematização dos registros, o que implica no aprimoramento da profissão, fator que demonstra a necessidade e temporalidade do início de produção científica sobre essa temática.
\end{abstract}

Palavras-chave: Registros, Documentação, Terapia Ocupacional, Educação Inclusiva.

\section{Record of Occupational Therapy interventional practice in inclusive education}

\begin{abstract}
Considering the importance of records in the professional practice of occupational therapy, it is necessary to instill a more insightful look at the effectiveness of practitioners' notes, as well as encourage the development of research-oriented documentary practice. The preparation of records arises from the need to have information from the service as a means of guidance and oversight of the service provided and on the adopted technical responsibility, as well as from the fact that the notes are a valuable data providing resource for research. The present study sought to identify and characterize occupational therapists in the state of Sao Paulo who work in inclusive education and how the records of their interventional practices are performed. A structured questionnaire as a tool available on the website for specific predetermined time was used as the study instrument, and the obtained data were analyzed using descriptive statistics. Participants were 55 occupational therapists working in the inclusive education process registered in the $3^{\text {rd }}$ region of the Regional Council of Physical Therapy and Occupational Therapy. The results demonstrated that free narrative was the most commonly used registration model and that information related to the process of custody of notes was fragmented. These data showed weakness in the systematization of records, which is believed to result in improvement of the profession, a factor that demonstrates the necessity and temporality of the scientific production on this issue.
\end{abstract}

Keywords: Records, Documentation, Occupational Therapy, Inclusive Education.

Autor para correspondência: Tatiana Barbieri Bombarda, Departamento de Terapia Ocupacional, Universidade Federal de São Carlos, Rodovia Washington Luís, Km 235, s/n, Jardim Guanabara, CEP 13565-905, São Carlos, SP, Brasil, e-mail: tatibb_to@yahoo.com.br 


\section{Introdução}

Historicamente, visualiza-se que a inserção do terapeuta ocupacional no âmbito escolar se dá por meio da Educação Especial, se estendendo para as escolas regulares com o movimento de inclusão, o qual se potencializa na década de 1990. De acordo com Lourenço e Cid (2010), o foco das intervenções tem se ampliado, considerando o desenvolvimento de açôes não apenas com os alunos, mas também direcionadas à escola, professores e familiares.

De forma significativa, é possível observar o desenvolvimento de açôes terapêuticas ocupacionais que transitam entre a normatização de comportamentos e desempenho funcional às ações voltadas ao processo ensino-aprendizagem e às relaçóes emergentes no contexto escolar (ROCHA, 2007).

Tão importante quanto o entendimento das práticas desenvolvidas são os registros das intervençôes realizadas, sendo esse procedimento parte fundamental do trabalho da Terapia Ocupacional.

O registro consiste nas anotaçóes realizadas pelos terapeutas ocupacionais com fins de documentar suas açóes profissionais englobando, portanto, as avaliaçóes, prescriçóes, orientaçôes e processo evolutivo.

Os registros são de extrema relevância para configuração da profissão, podendo essa importância ser classificada em:

Assistencial: Os registros servem de ferramenta para a comunicaçáo com a equipe e permitem a visualização cronológica das intervençôes desenvolvidas e resultados obtidos (FIGUEIREDO et al., 2007; STUMPF; FREITAS, 1997; NOVAES, 2003; POSSARI, 2007).

Administrativa: São fonte comprobatória da assistência prestada, provedores de informaçóes para o gerenciamento de custos, faturamento e de indicadores de qualidade do serviço (FIGUEIREDO et al., 2007; STUMPF; FREITAS, 1997; POSSARI, 2007; NOVAES, 2003).

Educacional: Fonte de dados para pesquisas, para estudos clínicos e epidemiológicos (FIGUEIREDO et al., 2007; STUMPF; FREITAS, 1997; NOVAES, 2003; POSSARI, 2007).

Jurídica: Legitima as ações assistenciais prestadas; são considerados meio de prova idônea para instruir processos disciplinares e a defesa legal, bem como servem de subsídios para a formulaçáo de políticas públicas (VASCONCELLOS; GRIBEL; MORAES, 2008; CONSELHO..., 2012).
É importante mencionar que não há na profissão um método padrão ou exclusivo para documentar os serviços de Terapia Ocupacional. Para tanto, os profissionais devem ter ciência da necessidade das anotaçóes denotarem concisão; de serem objetivas e completas, considerando que as imprecisões correlacionam-se com falhas na comunicação, implicando desfavoravelmente na atuação (MATTHEWS; JABRI, 2004).

Cientificamente, escassas são as publicaçôes envolvendo a temática dos registros de Terapia Ocupacional, sendo essas de predominância internacional e nenhuma delas concernente ao contexto escolar.

Apenas um estudo foi encontrado no âmbito nacional, o qual volta-se para a prática documental clínica na assistência ambulatorial. A pesquisa de Panzeri (2013) envolveu análise qualitativa de documentos jurídicos sobre a temática, concomitante à pesquisa de campo envolvendo a aplicação de um questionário voltado à percepção dos terapeutas ocupacionais em relação a elaboração de seus registros. Foram participantes desse estudo 104 terapeutas ocupacionais do estado de São Paulo, sendo coletados dados voltados a identificaçâo dos tipos de documentaçáo desenvolvidos, local de armazenamento, métodos utilizados, tempo gasto no registro e nível de satisfação dos respondentes para com sua documentação.

Em 2012, apesar de não se tratar de um estudo científico, verificou-se a publicação de um livro com abordagem multiprofissional sobre documentação em prontuário, com um capítulo específico acerca dos registros da profissão da Terapia Ocupacional, em que se expressam reflexóes envolvendo os referenciais que regem a prática clínica, sendo pontuados aspectos sobre a importância documental e de sua constituição, sem entretanto adentrar em práticas específicas das anotaçóes propriamente ditas (OLIVEIRA et al., 2012).

Com relação a embasamentos jurídicos, não foram encontradas normativas pelo Ministério da Educação correlacionadas a orientaçóes específicas acerca do método de registro dos profissionais que desenvolvem ações em interface com a saúde (considerando-se aqui terapeutas ocupacionais, psicólogos, fonoaudiólogos, entre outros).

Todavia, no Manual da Secretaria Escolar (BRASIL, 2010), verificou-se sucintamente informação relacionada a obrigatoriedade dos registros de avaliação processual, interventiva e funcional dos alunos da Educação Especial; sendo referido que a elaboração da documentaçáo deve ser efetivada de acordo com o regimento da instituição escolar. 
No Brasil, enquanto documentação jurídica direcionada ao ato do registro terapêutico ocupacional identificam-se especificamente três resoluções:

- Resolução 10/1978 - Aprova o Código de Ética da profissão da Fisioterapia e Terapia Ocupacional, onde está inserido no Capítulo II em seu artigo $14^{\circ}$ o dever do terapeuta ocupacional zelar para que o prontuário do cliente permaneça fora do alcance de estranhos à equipe de saúde da instituição, salvo quando outra conduta seja expressamente recomendada pela direção da instituição (CONSELHO..., 1978).

- Resolução 418/2012 - Fixa e estabelece parâmetros assistenciais terapêuticos ocupacionais nas diversas modalidades prestadas pelo terapeuta ocupacional, onde no item III do artigo $3^{\circ}$ é referido como responsabilidade do terapeuta ocupacional o registro sistemático da evolução do cliente/paciente e de sua conduta profissional, em prontuário e/ou registros pessoais e institucionais, segundo os critérios previstos em legislação específica (CONSELHO..., 2012a).

- Resolução 415/2012 - Dispóe acerca da obrigatoriedade do registro pelo terapeuta ocupacional, sobre a guarda, descarte e outras providências (CONSELHO..., 2012b).

Em específico, a Resolução 415, sancionada em maio de 2012 pelo Conselho Federal de Fisioterapia e Terapia Ocupacional - COFFITO, trata exclusivamente da obrigatoriedade dos registros clínicos dos terapeutas ocupacionais, apontando como composição mínima da documentação (CONSELHO..., 2012b):

- Identificação do cliente;

- História clínica;

- Exame clínico/educacional/social (de acordo com a semiologia terapêutica ocupacional);

- Exames complementares;

- Diagnóstico e prognóstico terapêutico ocupacional;

- Plano terapêutico ocupacional;

- Evolução da condição de saúde, qualidade de vida e participação social do cliente;

- Identificaçáo profissional: assinatura e número de registro no CREFITO.
De acordo com a resolução supracitada, a guarda do prontuário é de responsabilidade do terapeuta ocupacional e/ou da instituição onde a assistência for prestada e seu armazenamento deve corresponder a um período de guarda de no mínimo cinco anos, a contar do último registro.

A terminologia a ser adotada deve ser própria da profissão, devendo a redação ser clara e legível, havendo a opção de manuscrito e formato eletrônico.

Cabe ressaltar que o terapeuta ocupacional é obrigado a manter sigilo das informaçóes contidas em prontuário, sendo esse instrumento de pertencimento do cliente.

Nas escolas, sabe-se que além do prontuário do aluno há outras fontes de registros, como diários de classe, livros ata, fichas, meios magnéticos, sistemas informatizados de gestão escolar e outros, levando em consideração a natureza dos fatos (BRASIL, 2010).

Considerando-se que os registros das açôes dos terapeutas ocupacionais são um importante instrumento ético, profissional e jurídico, visualiza-se como necessário o início de investigaçôes dessa prática nas diferentes áreas de atuaçấo da Terapia Ocupacional, visando à busca de conhecimento científico como meio de viabilizaçáo de registros mais criteriosos, o que implica diretamente na qualidade assistencial e consequente aprimoramento da profissáo.

\section{Objetivo}

Identificar e caracterizar os terapeutas ocupacionais do estado de São Paulo que atuam na educação inclusiva e como são realizados os registros de suas práticas interventivas.

\section{Método}

Trata-se de um estudo transversal exploratório, envolvendo levantamento de campo de abordagem quantitativa (SAMPIERI; COLLADO; LUCIO, 2006).

\subsection{Sujeitos}

Participaram desta pesquisa terapeutas ocupacionais do estado de São Paulo atuantes no processo de inclusão escolar. Como critério de inclusão do estudo foram considerados terapeutas ocupacionais cadastrados no Conselho Regional de Fisioterapia e Terapia Ocupacional do Estado de Sáo Paulo (CREFITO-3) e com atuação em escola regular ou especial, à vista da compreensão, como princípio da inclusão escolar, a união entre esses dois sistemas enquanto garantia do direito à educação. 


\subsection{Instrumento}

O instrumento para a coleta de dados consistiu em um questionário estruturado desenvolvido pela própria pesquisadora, o qual foi enviado a três juízes para apreciação, sendo posteriormente realizadas adequaçóes sugeridas, as quais envolveram trocas de terminologia e inserção e/ou modificação de alternativas.

Como a disponibilização do questionário foi realizada por meio virtual, após as adequaçôes no instrumento realizou-se sua inserção em site da web, em plataforma de serviço específico de pesquisas on-line.

Foi realizado teste piloto por cinco terapeutas ocupacionais náo atuantes no contexto escolar (sujeitos náo pertencentes aos critérios de inclusão da pesquisa) para aferir a precisão do instrumento no molde virtual, sendo posteriormente realizados ajustes pertinentes ao seu melhor funcionamento.

Concluída tais etapas, o questionário foi disponibilizado em plataforma digital em site específico pelo período de 60 dias.

\subsection{Coleta de dados}

Para contato com os participantes foi realizado incialmente envio de ofício ao CREFITO-3 apresentando a proposta do estudo e solicitação de auxílio na divulgaçáo da pesquisa através de um mailing ${ }^{2}$, intermediando, portanto o contato com todos os terapeutas ocupacionais do estado de Sáo Paulo cadastrados nessa unidade.

Concomitantemente, em momentos distintos foram realizados envios de convites de participação no estudo, pela pesquisadora, por meio de e-mails a contatos pessoais, bem como divulgado em redes sociais específicas da profissão.

A divulgaçáo da mensagem convite consistiu na explicitaçáo do objetivo da pesquisa, de seu critério de inclusão, assim como informava o link que permitia o acesso ao questionário, comunicando a data de sua disponibilização no sistema on-line.

\subsection{Análise dos dados}

Após o levantamento de campo, os resultados obtidos foram analisados através de estatística descritiva.

\section{Resultados}

O estudo envolveu a participação de 55 terapeutas ocupacionais, sendo a média de idade dos participantes de 33 anos ( $\mathrm{dp}=9,75$ ), variando de 23 a 67 anos, apresentando a mediana de valor igual a 29,5 anos.
A amostra foi composta predominantemente pelo gênero feminino, com apenas um respondente do sexo masculino.

Em relação ao vínculo empregatício, 29,1\% dos sujeitos afirmaram realizar consultoria ${ }^{3}$, $23,6 \%$ referiram serem prestadores de serviço ${ }^{4}$ e $47,3 \%$ dos profissionais sinalizaram trabalhar em regime CLT $^{5}$. Com relação a natureza da instituição escolar, o grupo respondente mostrou-se equilibrado, sendo 26 terapeutas ocupacionais atuantes em escolas regulares e 29 em escolas especiais.

Referente ao tempo de atuaçáo no contexto escolar foi verificada predominância de participantes com experiência acima de um ano $(70,91 \%)$.

Concernente às açôes desenvolvidas pelos terapeutas ocupacionais, os participantes puderam assinalar mais do que uma alternativa, sendo apontado enquanto práticas assistenciais açôes com alunos (98,2\%), com professores $(69,09 \%)$, no espaço escolar (52,73\%), com pais/responsáveis (16,36\%), funcionários de apoio (7,27\%) e gestores (3,64\%).

Em específico sobre a caracterização da documentação, verificou-se que a realização dos registros de forma manuscrita é feita por $54,5 \%$ dos terapeutas ocupacionais, seguida por $40 \%$ de profissionais que realizam registros mistos (manuscrito + informatizado). Já a elaboração do registro exclusivamente informatizado foi mencionada por apenas $5,5 \% \mathrm{da}$ amostra.

O modelo mais utilizado para os registros é o da narrativa livre $(56,40 \%)$ seguido por roteiro predefinido pela escola $(14,54 \%)$, sendo dados acerca da rotina documental expressos na Tabela 1 .

Outro aspecto investigado consistiu na existência do serviço de terapia ocupacional anterior a atuação do participante e registros dessa prática prévia. Em 56,4\% das respostas foi mencionado que a instituição escolar já havia recebido algum tipo de intervençáo por outro terapeuta ocupacional, havendo em $80,6 \%$ dos casos documentação acerca desse trabalho, sendo $48 \%$ indicados como náo efetivos, ou seja, como não contendo informaçôes suficientes para entendimento situacional e possibilidades de seguimento.

É importante destacar que 89,1\% dos profissionais afirmaram desconhecer a Resolução 415 sancionada pelo COFFITO em maio de 2012 que, conforme apresentado introdutoriamente, consiste em informações específicas da constituição da documentação terapêutica ocupacional. 
Tabela 1. Rotina da documentação do terapeuta ocupacional no âmbito escolar.

\begin{tabular}{|c|c|c|}
\hline Disposição dos registros & N (55) & $\%$ \\
\hline Variações de disposição ocorrem de acordo com a intervenção realizada & 14 & 25,5 \\
\hline Somente prontuário multi ou interdisciplinar & 11 & 20 \\
\hline Parte em prontuário multi ou interdisciplinar e parte em prontuário específico da TO & 9 & 16,4 \\
\hline Somente prontuário específico da TO & 8 & 14,5 \\
\hline Parte prontuário do aluno e parte prontuário específico da TO & 7 & 12,7 \\
\hline Somente prontuário do aluno & 6 & 10,9 \\
\hline Armazenamento dos registros & N (55) & $\%$ \\
\hline Prontuário do aluno & 22 & 40 \\
\hline Variações de armazenamento ocorrem de acordo com a intervenção realizada & 12 & 21,8 \\
\hline Outros* & 10 & 18,2 \\
\hline Coordenação pedagógica na escola & 8 & 14,5 \\
\hline Diretoria escolar & 2 & 3,6 \\
\hline Secretaria da Educação & 1 & 1,8 \\
\hline Frequência da realização dos registros & N (55) & $\%$ \\
\hline Ao final de cada atividade/intervenção & 20 & 36,4 \\
\hline Diariamente & 15 & 27,3 \\
\hline Pelo menos uma vez por semana & 7 & 12,7 \\
\hline Pelo menos uma vez por mês & 7 & 12,7 \\
\hline Praticamente todos os dias & 2 & 3,6 \\
\hline Muito raro & 4 & 7,3 \\
\hline
\end{tabular}

*Com relação ao armazenamento dos registros foram acrescentadas pelos participantes referências de guarda nas salas de atendimento, sala de prontuário multiprofissional e armazenagem na instituição de trabalho, nos casos de parcerias e de extensão clínica, sendo mencionado nesses casos envio de cópia da documentação à escola.

\section{Discussão}

Ao analisar os dados referente a caracterização da amostra, visualizou-se que a mediana encontrada foi de 29,5 anos, o que denota a inserçáo no contexto escolar de terapeutas ocupacionais jovens, fator hipoteticamente atrelado a relação das demandas emergentes no campo educacional e a expansão das açôes interventivas terapêuticas ocupacionais, sinalizando maior abertura aos profissionais na área da Educação.

A abrangência de participantes do gênero feminino já era prevista, considerando informaçóes estatísticas dos profissionais do estado de Sáo Paulo, no qual, dos 4.731 terapeutas ocupacionais cadastrados, $4.577^{6}$ são do sexo feminino e apenas 154 do sexo masculino.

O vínculo empregatício dos participantes envolveu práticas de consultorias $(29,1 \%)$, prestaçóes de serviços (23,6\%) e trabalho em regime CLT (47,3\%), podendo ser percebida pontualmente em algumas questôes diferenças na prática documental. Houve um equilíbrio entre a participação de terapeutas ocupacionais que trabalham em escolas regulares $(n=26)$ e em escolas especiais $(n=29)$, fator que também permitiu de forma ampla a visualização de semelhanças e diferenças na sistemática dos registros, indicativo de possibilidades de novos estudos mais aprofundados por categorias.

Foi possível notar que no contexto especial a atuação ainda constitui estruturalmente seu molde na reabilitação, sendo a sistemática documental apresentada com maior frequência com fluxo melhor estabelecido: local fixo de armazenamento e guarda do prontuário do aluno, bem como sala própria para realização de evoluções clínicas multiprofissionais.

No âmbito das escolas regulares, percebeu-se maior variabilidade dos registros, desde sua realizaçáo à guarda, fator associado aos diferentes vínculos empregatícios e ao direcionamento das açôes apontadas mais para o processo ensino-aprendizagem.

A identificação de açôes voltadas ao aluno, à família, à equipe envolvida e ao espaço escolar, segundo Bartalotti (2004), demonstram que a Terapia Ocupacional, além de aprimorar suas técnicas interventivas voltadas às incapacidades emergidas pela deficiência, com abordagens de reabilitação, tem buscado voltar-se cada vez mais ao contexto social em que o sujeito está inserido, reconstruindo o seu cotidiano a partir da transformação da comunidade envolvida, fato que justifica a atuação profissional com os educadores, familiares e com a sociedade.

Em específico sobre o ato de documentar observou-se predominância pelo formato manual 
(54,5\%), seguido por $40 \%$ de registros mistos (manuscrito + informatizado), dados compatíveis aos encontrados na pesquisa de Panzeri (2013) voltada aos registros realizados por terapeutas ocupacionais no contexto ambulatorial clínico, sinalizando a realizaçấo de $64,4 \%$ de anotaçôes manuais e $26 \%$ de registros mistos.

A prática manuscrita traz a reflexáo sobre a qualidade, em específico de um dos critérios importantes à documentação: a legibilidade. Apesar de náo terem sido encontrados estudos referentes à investigação dos registros realizados por terapeutas ocupacionais envolvendo essa variável, nas pesquisas de Scochi (1994), Stumpf e Freitas (1997) e de Luz, Martins e Dynewicz (2007), que envolveram a investigação documental em áreas da saúde, menciona-se entre os resultados informaçóes concernentes a dados ilegíveis, demonstrando ser essa uma problemática já diagnosticada em diferentes especialidades.

Com os avanços tecnológicos, acredita-se que a informatização das anotações vem aumentando significativamente nas últimas décadas. Hipoteticamente, supóe-se que a parte informatizada dos registros mistos no âmbito escolar esteja em sua maioria vinculada a relatórios e documentaçôes administrativas do que a anotaçôes do processo interventivo.

Uma vantagem da informatização das anotações é a garantia do requisito da legibilidade. A informação clara e legível minimiza dificuldades referentes ao processo de compreensão da assistência prestada por outros componentes da equipe, contribuindo para um alinhamento multi/interdisciplinar das açóes em prol do aluno.

Figueiredo et al. (2007) referem que o registro em papel, negativamente, pode implicar não apenas no aspecto da legibilidade, mas também na facilidade de perda das informaçôes contidas no prontuário. Contudo, os autores também expressam que a prática manuscrita apresenta a vantagem de assegurar a validade legal da documentação, não deixando desconfianças sobre a assinatura do profissional, visto que a assinatura digital pode dar margens a dúvidas.

Enfatiza-se que a anotação legível é um requisito que consta na Resolução 415 do COFFITO e também no manual da Secretaria Escolar (BRASIL, 2010), sendo outros princípios em comuns desses documentos a objetividade e a clareza das informaçóes.

Enquanto tipo de registro mais utilizado para a prática documental foi verificado a narrativa livre, dado também compatível ao encontrado por Panzeri (2013) no contexto da documentaçáo dos terapeutas ocupacionais atuantes em ambulatórios. A narrativa consiste no ato de redigir cronologicamente informaçóes acerca das intervençóes realizadas e sobre o cliente, não havendo um formato pré-estruturado; podendo para tanto existir variáveis de acordo com o profissional que o faz (TIMBY, 2007). Por se tratar de uma escrita descritiva, esse modelo é considerado como mais difícil para a busca de informaçóes peculiares, considerando-se o tempo gasto e a necessidade da leitura do todo para a visualizaçáo de dados específicos.

Ilha (1994) refere que a manipulação de todo o conjunto de informaçóes existentes nos registros torna muito difícil a utilização da anotação como ferramenta de suporte à avaliação do desempenho das instituiçóes, de resultados obtidos ou mesmo para a aquisição de novos conhecimentos.

Considerando que não há na Terapia Ocupacional um método padrão ou exclusivo para documentação de suas práticas, hipoteticamente, o uso da narrativa livre pode estar vinculado a formação recebida na graduação desses profissionais, bem como estar associada à carência de instrumentos específicos da profissão voltados a avaliaçôes e mensuração de resultados obtidos.

Alguns modelos para a documentação são apontados na literatura específica da profissão, como o Registro Médico Orientado para o Problema - RMOP, o Registro Sequencial de Atendimento ao Paciente em Terapia Ocupacional - RSAPTO, o sistema de anotaçôes de progresso Subjective Objective Assessment Plan - SOAP e a Classificaçáo Internacional de Funcionalidade - CIF. Tais modelos apresentam, enquanto cerne, uma estruturação predominantemente biomédica, sendo voltados a área da saúde. Com a extensão da práxis profissional para área Social e da Educação, há necessidade de discussões sobre formas avaliativas das açóes realizadas, elaboraçóes de protocolos e, em específico, de publicaçóes sobre a documentação nos diferentes contextos de atuação da Terapia Ocupacional.

Em relação à disposição dos registros, observa-se um percentual de $54,54 \%$ de respostas que sinalizam que as informaçóes ficam dispostas separadamente em prontuários distintos (parte em prontuário do aluno, parte em prontuário da $\mathrm{TO}$ ou; parte em prontuário multi/interdisciplinar e parte em prontuário específico da $\mathrm{TO}$ ), assim como que variaçôes na disposição ocorrem de acordo com o tipo de intervenção realizada. Tais afirmativas demonstram uma segregação dos dados, o que, acredita-se, possa dificultar a visualização não só pelo terapeuta ocupacional mas pelos profissionais $\mathrm{da}$ equipe acerca do processo terapêutico contínuo, fator que implica desfavoravelmente na atuação profissional, 
na percepção de ganhos e, consequentemente, na valorização do trabalho desempenhado.

A segregação das informaçôes também foi observada no armazenamento dos registros, considerando a indicação por $21,8 \%$ de participantes que afirmam que a guarda das anotaçóes sofrem variação de acordo com a intervenção realizada. Além disso, outro fator de alerta é a sinalização de armazenamento dos registros na diretoria escolar e na Secretaria da Educação, locais que evidenciam uma barreira maior ao acesso dessas anotaçóes para aqueles profissionais que poderiam fazer uso de tais informações.

Considerando que o registro é uma ferramenta importante de comunicação com a equipe, os aspectos de legibilidade, de disposição e guarda devem ser merecedores de maior atenção pelos profissionais, visto que a sistematização das anotaçóes não consiste apenas no ato de redigir, mas sim na incorporação do valor da documentação, a qual entre outros aspectos deve servir como recurso de difusão do trabalho realizado e de diálogo entre os profissionais, o que tendenciosamente leva a uma maior integralidade das açóes interdisciplinares e que permite uma assistência contínua.

A fragilidade na sistematização dos registros torna-se ainda mais visível ao se analisarem dados referente a frequência com que os terapeutas ocupacionais praticam a documentação no âmbito escolar. A somatória de respostas envolvendo a realização de anotações semanais, mensais e como muito raras engloba 32,7\% dos participantes. Há de se atentar que juridicamente os registros são obrigatórios sempre que houver atividade assistencial prestada. $\mathrm{O}$ fato de nem toda intervenção ser registrada pode ocasionar falhas na comunicação com outros profissionais, implicar em prejuízos financeiros considerando que a documentação é utilizada enquanto instrumento comprobatório para fonte de pagamento, bem como impedir continuidade assistencial por outro terapeuta ocupacional que possa vir a assumir o caso.

A continuidade assistencial só é possível à medida que são registradas informaçôes consistentes acerca do aluno, das problemáticas apresentadas e condutas adotadas pelo terapeuta ocupacional. Contudo, é preocupante a análise dos dados referente a afirmação por 31 participantes de que a instituição escolar já havia recebido algum tipo de intervenção por outro terapeuta ocupacional, não havendo em 19,4\% registros sobre a assistência prestada. Além disso, nos 80,6\% de afirmação acerca da existência da documentação desse trabalho prévio, $48 \%$ foram indicados como não contendo informaçóes suficientes para entendimento e seguimento.
Há de se atentar que se na avaliação dos próprios terapeutas ocupacionais sobre a documentação de seus colegas foi observada estruturação precária e dificuldades para compreensão da prática efetivada, torna-se questionável o quão inteligível os registros terapêuticos ocupacionais são para profissionais de outras especialidades.

$\mathrm{Na}$ pesquisa de Hedberg-Kristensson e Iarwsson (2003), 182 registros terapêuticos ocupacionais envolvendo o processo de prescrição de tecnologia assistiva foram analisados em dois municípios suecos, sendo a documentação classificada como deficitária considerando-se a verificação de informaçóes inconsistentes e ausência de anotaçôes em diferentes itens avaliados.

Dados publicados na Revista de Terapia Ocupacional do Conselho Regional de Fisioterapia e Terapia Ocupacional da 3a Região - CREFITO-3 também abordam a questão da documentação por meio de informaçóes do departamento de fiscalização (DEFIs) e a realização de 53 autuaçóes em estabelecimentos da cidade de Sáo Paulo no mês de agosto de 2013, sendo nove das notificações referentes a ausência de prontuário com evolução do paciente (CONSELHO..., 2013), dados que vão ao encontro da problemática aqui sinalizada.

Em maio de 2012 foi sancionada pelo COFFITO a Resolução 415, sendo essa uma normativa voltada a estruturação mínima da documentação da Terapia Ocupacional. Apesar de ser esse um passo importante no constructo da profissão, verificou-se que $89,1 \%$ dos participantes desconhecem a resolução, evidenciando que legislaçóes conjecturadas para auxiliar os profissionais em seu desempenho podem apresentar-se como não efetivas, considerando diferentes fatores, entre eles o de falhas vinculadas a divulgação.

Acredita-se que essa resolução, apesar de não denotar especificidades por campos de atuação, constitui importante instrumento profissional e um recurso favorável ao desenvolvimento da Terapia Ocupacional. Contudo, é necessário que as legislaçóes não sejam apenas formuladas mas sim disseminadas entre os terapeutas ocupacionais e que sejam construídas a partir da realidade vivenciada nas práticas profissionais.

É preciso que os terapeutas ocupacionais sejam estimulados a se apoderarem dos dispostos legislativos e para isso, primeiramente, torna-se necessário aproximar os profissionais de seus órgãos representativos, minimizando barreiras, em especial a da comunicação. 
A sistemática dos registros aqui investigada com um recorte na educação inclusiva, sugere mediante a identificação dos dados apresentados indicadores de falhas processuais na elaboração dos registros, $\mathrm{o}$ que certamente compromete a qualidade assistencial.

É importante ressaltar que a documentação é um ato jurídico e fornecedora de subsídios para práticas adequadas e desenvolvimento de pesquisas, sendo, para tanto, necessário o investimento em estudos envolvendo essa temática, considerando as diversas variáveis envolvidas no processo documental como tempo, orientaçóes e treinamentos recebidos, modelos utilizados, uso de terminologias adequadas, locais de busca de conhecimento para a prática de registro, nível de satisfação com as anotaçôes efetivadas, entre outras.

\section{Considerações finais}

A documentação tem grande valor para o desenvolvimento da profissão, considerando ser o registro uma ferramenta de comunicaçáo entre os profissionais, proveniente da necessidade de se possuir informações decorrentes da assistência prestada como via de orientação e fiscalização, bem como de consistir em subsídios para pagamento do trabalho desenvolvido.

Considerando-se que a importância dos registros abrange aspectos jurídicos, administrativos e assistenciais, torna-se necessário fomentar a discussão sobre essa temática e incentivar o início de investigaçôes sobre a qualidade das anotações desenvolvidas pelos terapeutas ocupacionais em seus diferentes campos de atuação.

Em especial, no âmbito escolar, visualizou-se dados indicativos de uma fragilidade na sistemática dos registros, despertando focos para novas pesquisas em prol de se instituir anotaçôes mais criteriosas e favorecedoras de um maior aprimoramento da profissão.

É importante explicitar que enquanto limitaçôes deste estudo podem ser apontadas a utilizaçáo de uma amostra reduzida, as escassas publicaçóes existentes sobre a temática e o tempo disponível para a realização do estudo.

A escolha metodológica que envolveu a aplicação de um questionário por meio virtual, apesar de otimizar o acesso aos terapeutas ocupacionais do estado de São Paulo também pode ser considerada um fator limitante deste estudo, visto a constatação de grande perda percentual de participação. Acredita-se que as desistências possam estar atreladas à insegurança dos participantes em prover dados pessoais pela web, considerando que a maioria das cessaçóes ocorreu logo no início do questionário, em que foi solicitada a inserção de informaçóes pessoais (nome completo, data de nascimento e número do CREFITO-3) visando maior fidedignidade dos dados, todavia, podem ter sido fatores que implicaram na redução da amostra.

As escassas publicações envolvendo a sistemática de registros, em especial no Brasil, torna limitante o apontamento de proposiçóes para melhorias, sendo necessário o aprofundamento de novos estudos acerca dessa temática para posterior discussão ampliada e enriquecedora que permita em seus desdobramentos a apresentação de propostas efetivas direcionadas a registros de melhor qualidade.

Outro fator a ser considerado é o tempo, visto proposta inicial de, além da aplicação do questionário, realizar visitas para investigaçáo dos prontuários ao menos em quatro escolas selecionadas aleatoriamente. Contudo, mediante o cumprimento de prazos, não foi possível o desenvolvimento dessa segunda etapa, o que impediu a relação neste momento, dos aspectos relatados sob a óptica profissional e as informaçôes coletadas in loco.

Em contrapartida, este estudo permitiu a visualização de novos focos investigativos envolvendo a temática documental, como o desenvolvimento de pesquisas por categorias de escola (especial e regular) considerando diferenciaçóes existentes na prática interventiva e, consequentemente, na sistematização de registros; a investigação da terminologia técnica utilizada pelos profissionais, bem como a avaliação da ênfase dada aos registros pelos docentes dos cursos de formação em Terapia Ocupacional e as metodologias envolvidas no processo desse ensino.

De forma geral, este estudo permitiu uma aproximação investigativa com a temática, demonstrando dados que evidenciam a temporalidade dessa discussão dentro da Terapia Ocupacional. Percebe-se como necessário aprimorar o estabelecimento da linguagem, desenvolver instrumentos próprios de avaliação, estabelecer critérios mais estruturados para a prática documental e envolver investimentos na capacitação profissional e na formação acadêmica dos terapeutas ocupacionais. A presente pesquisa mostrou ainda que se faz necessário o investimento de novos estudos para o entendimento situacional da documentação na educação inclusiva, para aprimoramento da qualidade dos registros.

\section{Referências}

BARTALOTTI, C. C. A inclusão social da pessoa com deficiência e o papel da Terapia Ocupacional. Cidadania e Justiça, Brasília, v. 7, n. 13, p. 165-174, 2004. 
BRASIL. Secretaria de Estado de Educação. Coordenação de Supervisão Institucional e Normas de Ensino. Manual da Secretaria Escolar. Brasília, 2010.

CONSELHO FEDERAL DE FISIOTERAPIA E TERAPIA OCUPACIONAL - COFFITO. Resolução no 10, de 3 de julho de 1978. Aprova o código de ética profissional de fisioterapia e terapia ocupacional. Diário Oficial da Uniāo, Poder Executivo, Brasília, DF, 22 set. 1978. Disponível em: <http://www.coffito.org.br/site/ index.php/home/resolucoes-coffito/81-resolucao-n-10-aprova-o-codigo-de-etica-profissional-de-fisioterapia-e-terapia-ocupacional.html>. Acesso em: 8 ago. 2013.

CONSELHO FEDERAL DE FISIOTERAPIA E TERAPIA OCUPACIONAL - COFFITO. Resolução no 418, de 4 de junho de 2012. Fixa e estabelece os parâmetros assistenciais Terapêuticos Ocupacionais nas diversas modalidades prestadas pelo terapeuta ocupacional e dá outras providências. Diário Oficial da União, Poder Executivo, Brasília, DF, 6 de junho de 2012a. Disponível em: <http://www.coffito.org.br/site/index.php/home/ resolucoes-coffito/497-resolucao-n-418-2012-fixa-e-estabelece-os-parametros-assistenciais-terapeuticos-ocupacionais-nas-diversas-modalidades-prestadas-pelo-terapeuta-ocupacional-e-da-outras-providencias.html>. Acesso em: 8 ago. 2013.

CONSELHO FEDERAL DE FISIOTERAPIA E TERAPIA OCUPACIONAL - COFFITO. Resolução $n^{\circ}$ 415 , de 19 de maio de 2012. Dispóe sobre a obrigatoriedade do registro em prontuário pelo terapeuta ocupacional, da guarda e do seu descarte e dá outras providências. Diário Oficial da Uniāo, Poder Executivo, Brasília, DF, 23 maio 2012b. Disponível em: <http://www.coffito.org. br/publicacoes/pub_view.asp? $\operatorname{cod}=2257 \&$ psecao $=9>$. Acesso em: 30 ago. 2012.

CONSELHO REGIONAL DE FISIOTERAPIA E TERAPIA OCUPACIONAL - CREFITO. Estratégia da fiscalização na capital concentra atuação por bairros. Terapia Ocupacional em Revista, São Paulo, v. 1, n. 3, p. 26, 2013.

FIGUEIREDO, L. T. et al. Prontuário eletrônico do paciente: a funcionalidade do registro informatizado. Revista de Enfermagem UFPE Online, Joáo Pessoa, v. 1, n. 2, p. 225-232, 2007. Disponível em: <http://www. revista.ufpe.br/revistaenfermagem/index.php/revista/ article/viewFile/389/pdf_193 >. Acesso em: 7 abr. 2013.

HEDBERG-KRISTENSSON, E.; IWARSSON, S. Documentation quality in occupational therapy patients records: focusing on the technical aid prescription process. Scandinavian Journal of Occupational Therapy, Oslo, v. 10, n. 2, p. 72-80, 2003. http://dx.doi. org/10.1080/11038120310009434.

ILHA, J. O. O registro clínico computadorizado: funçóes e vantagens. Revista Informédica, Campinas, v. 1, n. 7, p. 5-10, 1994.

LOURENÇO, G. F.; CID, M. F. B. Possibilidades de ação da terapia ocupacional na educação infantil: con- gruência com a proposta da educação inclusiva. Cadernos de Terapia Ocupacional da UFSCar, São Carlos, v. 18, n. 2, p. 169-179, 2010.

LUZ, A.; MARTINS, A. P.; DYNEWICZ, A. M. Características de anotaçóes de enfermagem encontradas em auditoria. Revista Eletrônica de Enfermagem, Goiás, v. 9, n. 2, p. 344-361, 2007. Disponível em: <http://www. fen.ufg.br/revista/v9/n2/v9n2a05.htm>. Acesso em: 10 nov. 2013.

MATTHEWS, M. M.; JABRI, J. L. Documentação dos serviços de Terapia Ocupacional. In: PEDRETTI, L. W.; EARLY, M. B. Terapia ocupacional: capacidades práticas para disfunçôes físicas. São Paulo: Roca, 2004. p. 98-107.

NOVAES, H. M. D. A evolução do registro médico. In: MASSAD, E.; MARIN, H. F; AZEVEDO NETO, R. S. (Org.). O prontuário eletrônico na assistência, informação e conhecimento médico. São Paulo: H. de F. Marin, 2003. p.39-46.

OLIVEIRA, A. S. et al. Terapia ocupacional. In: GALVÃO, M. C. B.; RICARTE, I. L. M. Prontuário do paciente. Rio de Janeiro: Guanabara Koogan, 2012. p. 207- 221.

PANZERI, C. S. B. A prática da documentação clínica ambulatorial sob a ótica dos terapeutas ocupacionais. 2013. 166 f. Dissertação (Mestrado em Terapia Ocupacional)-Universidade Federal de São Carlos, São Carlos, 2013.

POSSARI, J. F. Prontuário do paciente. In: Prontuário do paciente e os registros de enfermagem. São Paulo: Látria, 2007. p. 17-34.

ROCHA, E. F. A Terapia Ocupacional e as açóes na educação: aprofundando interfaces. Revista de Terapia Ocupacional da Universidade de São Paulo, São Paulo, v. 18, n. 3, p. 122-127, 2007.

SAMPIERI, R. H.; COLLADO, C. F.; LUCIO, P. B. Metodologia de pesquisa. São Paulo: McGraw-Hill, 2006.

SCOCHI, M. J. Indicadores da qualidade dos registros e da assistência ambulatorial em Maringá, (estado do Paraná, Brasil), 1991: um exercício de avaliação. Cadernos de Saude Publica, Rio de Janeiro, v. 10, n. 3, p. 356-367, 1994. http://dx.doi.org/10.1590/S0102-311X1994000300015. PMid:14762544

STUMPF, M. K.; FREITAS, H. M. R. A gestão da informação em um hospital universitário: o processo de definição do Patient Core Record. Revista de Administração Contemporânea, Curitiba, v. 1, n. 1, p. 71-99, 1997.

TIMBY, B. K. Registro e relato. In: Conceitos e habilidades fundamentais no atendimento de enfermagem. Porto Alegre: Artmed, 2007. p. 120-137.

VASCONCELLOS, M. M.; GRIBEL, E. B.; MORAES, I. H. S. Registros em saúde: avaliação da qualidade do prontuário do paciente na atenção básica. Cadernos de Saude Publica, Rio de Janeiro, v. 24, p. 173-182, 2008. Suplemento 1. http://dx.doi.org/10.1590/S0102$-311 X 2008001300021$. 


\section{Contribuição dos Autores}

Tatiana Barbieri Bombarda: Concepção do texto, coleta de dados, organização de fontes e análises. Marina Silveira Palhares: Orientação e revisão do texto.

\section{Notas}

${ }^{1} \mathrm{O}$ material consiste em dados parciais da dissertação de mestrado "A prática de registro dos terapeutas ocupacionais na Educação Inclusiva”, realizada no Programa de Pós-Graduação em Terapia Ocupacional - PPGTO da Universidade Federal de São Carlos, defendida em 2014, sendo aprovada pelo Comitê de Ética em Pesquisa em Seres Humanos da mesma instituição mediante parecer n. 157.611.

${ }^{2}$ Mailing, de acordo com o dicionário de inglês-português on-line (http://www.wordreference.com/enpt/mailing) corresponde ao armazenamento de dados, os quais são utilizados para marketing direto (mala direta, correio eletrônico, postais).

${ }^{3}$ De acordo com o dicionário on-line Priberam da língua portuguesa http://www.priberam.pt/dlpo/consultorias, consultoria refere-se à atividade de quem dá pareceres e trata de assuntos técnicos de sua especialidade, em um espaço de tempo previamente determinado entre contratante e consultor.

${ }^{4}$ Prestação de serviço - desempenho da jornada de trabalho profissional com carga horária determinada, porém sem vínculo celetista (http://www.priberam.pt/dlpo).

${ }^{5}$ CLT $=$ regime celetista. Refere-se ao vínculo laboral que se rege pela Consolidação das Leis do Trabalho, norma legislativa brasileira relativa ao direito do trabalhador (http://www.priberam.pt/dlpo)

${ }^{6} \mathrm{O}$ número discriminado por gênero foi obtido através de consulta ao site do CREFITO-3 (http://www.crefito.com. br/app_site/est_prof.asp) em 2 de setembro de 2013, não sendo fornecidas informaçóes acerca do último período de atualizaçáo. 